\title{
Investigation of the hydraulic unit operation features based on vibration system data mining
}

\author{
Tatiana Penkova ${ }^{1,2}$, Anna Korobko ${ }^{1}$ \\ ${ }^{1}$ Institute of Computational Modelling of the Siberian Branch \\ of the Russian Academy of Sciences, 50/44 Akademgorodok, Krasnoyarsk, 660036, Russia \\ ${ }^{2}$ Siberian Federal University, 79 Svobodny pr., 660041 Krasnoyarsk, Russia \\ Penkova_teicm.krasn.ru
}

\begin{abstract}
The software and hardware level used for on-line monitoring of the hydropower equipment functioning parameters as well as the large amounts of stored data create the necessary conditions for application of innovative methods and technologies of data analysis in the tasks of analytical assessment of equipment condition. This paper presents the results of detecting the operational patterns of the hydraulic unit in various modes and functioning conditions based on the data mining techniques - principal component analysis and cluster analysis - applied to the monitoring data of the vibration control system. In multidimensional data space, two principal components have been selected and interpreted taking into account the contribution of the data attributes to the principal components. On the plane of the first two principal components, a five-cluster structure has been constructed to define the moments of time when the system demonstrates a characteristic behaviour. In addition, the monitored parameters have been analysed in terms of time series at characteristic moments of time. As a result, the comprehensive multidimensional analysis of monitoring data has allowed us to discover the hydraulic unit operation patterns and dependencies, determine the character of the influence induced by its constructive elements and work out the ratio between the ranges of key parameters in various modes of equipment operation.
\end{abstract}

Keywords: Multi-dimensional Data Analysis, Principal Component Analysis, Cluster Analysis, Vibration Control System, Hydropower Equipment, Estimation of Technical Condition.

\section{Introduction}

Modern requirements for cost-effective maintenance of equipment dictate the need to shift from scheduled preventive maintenance to maintenance and repair of equipment based on its technical condition [1-4]. At present, the guidelines in the field of hydroelectric power plants establish monitoring requirements for the state of hydropower equipment during operation and determine the rules and procedure for forming an integral assessment of the technical condition of the main equipment $[5,6]$. The level of software and hardware used for on-line monitoring of the functioning parameters of 
hydropower equipment, as well as the large amounts of accumulated data, create the necessary conditions for application of innovative methods and technologies of data analysis in the tasks of the analytical assessment of equipment condition without interruptions in its operation [7]. This work is aimed at detecting and studying the operational patterns of the hydraulic unit in various modes and conditions by considering the mutual influence of functional elements based on the application of principal component analysis and cluster analysis to the monitoring data of the vibration control system. Principal component analysis (PCA) is one of the most common techniques used to describe variation patterns in multidimensional data and one of the simplest and most robust ways of doing dimensionality reduction. PCA is a mathematical procedure that uses an orthogonal transformation to convert a set of observations of possibly correlated variables into a set of values of linearly uncorrelated variables called principal components [8]. Cluster analysis is a tool for discovering and identifying associations and structure within the data. Cluster analysis provides insight into the data by dividing the dataset of objects into groups (i.e. clusters) of objects, so that objects in a cluster are more similar to each other than to objects in other clusters [9]. Data mining techniques provide an effective tool for discovering previously unknown, nontrivial, practically useful and interpreted knowledge needed to make decisions [10].

This paper presents a comprehensive multi-dimensional analysis of monitoring data of the vibration control system for one of the hydraulic units of the Hydroelectric Power Station for the period from 25 June 2015 to 15 September 2015. In multidimensional data space, two principal components were selected and interpreted taking into account the contribution of the data attributes to the principal components. On the plane of the first two principal components, a five-cluster structure was constructed to define the moments of time when the system demonstrates a characteristic behaviour. In addition, the monitored parameters were analysed in terms of time series at characteristic moments of time. As a result, the comprehensive analysis of monitoring data allowed us to discover patterns and dependencies in the hydraulic unit operation, determine the character of the influence induced by its constructive elements and work out the ratio between the ranges of key parameters in various modes of equipment operation. Within this research, the analysis and visualisation of multidimensional data were conducted using the ViDaExpert tools [11].

The outline of this paper is as follows: Section 1 contains the introduction. Section 2 describes the original monitoring data. Section 3 presents the results of the principal component analysis: identification and interpretation of principal components. Section 4 presents the results of cluster analysis: construction of the five-cluster structure and detailed analysis of data distribution on the clusters by considering the values of key parameters. Section 5 contains the conclusions.

\section{Monitoring Data Description}

According to the theory of multi-dimensional data analysis, the original data are represented as a set of objects and a set of attributes. The set of objects contains the mo- 
ments of time in the hydraulic unit operation throughout three months (i.e. from 07:00 am 25 June 2015 to 11:00 pm 15 September 2015) aggregated by hour. The set of attributes contains the parameters registered by Automated Control System of Technological Processes and Vibration Control System. Controlled parameters are measured by sensors located on the equipment on the left bank and on the downstream side. Data attributes are listed in Table 1.

Table 1. List of the data attributes.

\begin{tabular}{|c|c|c|}
\hline No & Attribute & Description \\
\hline 1 & A_POWER & Active power, MW \\
\hline 2 & R_POWER & Reactive power, MW \\
\hline 3 & RV_GB_DS & $\begin{array}{l}\text { Relative vibration of the generator bearing } \\
\text { (downstream, radially), } \mu \mathrm{m}\end{array}$ \\
\hline 4 & RV_GB_LB & $\begin{array}{l}\text { Relative vibration of the generator bearing } \\
\text { (left bank, radially), } \mu \mathrm{m}\end{array}$ \\
\hline 5 & RV_HB_DS & $\begin{array}{l}\text { Relative vibration of the heel of the thrust bearing } \\
\text { (downstream, vertically), } \mu \mathrm{m}\end{array}$ \\
\hline 6 & RV_HB_LB & $\begin{array}{l}\text { Relative vibration of the heel of the thrust bearing } \\
\text { (left bank, vertically), } \mu \mathrm{m}\end{array}$ \\
\hline 7 & RV_TB_DS & $\begin{array}{l}\text { Relative vibration of the turbine bearing } \\
\text { (downstream, radially), } \mu \mathrm{m}\end{array}$ \\
\hline 8 & RV_TB_LB & $\begin{array}{l}\text { Relative vibration of the turbine bearing } \\
\text { (left bank, radially), } \mu \mathrm{m}\end{array}$ \\
\hline 9 & AV_GB_DS & $\begin{array}{l}\text { Absolute vibration of the generator bearing } \\
\text { (downstream, radially), } \mu \mathrm{m}\end{array}$ \\
\hline 10 & AV_GB_LB & $\begin{array}{l}\text { Absolute vibration of the generator bearing } \\
\text { (left bank, radially), } \mu \mathrm{m}\end{array}$ \\
\hline 11 & AV_FH_DS & $\begin{array}{l}\text { Absolute vibration of the heel of the thrust bearing } \\
\text { (downstream, vertically), } \mu \mathrm{m}\end{array}$ \\
\hline 12 & AV_FH_LB & $\begin{array}{l}\text { Absolute vibration of the heel of the thrust bearing } \\
\text { (left bank, vertically), } \mu \mathrm{m}\end{array}$ \\
\hline 13 & AV_TB_DS & $\begin{array}{l}\text { Absolute vibration of the turbine bearing } \\
\text { (downstream, radially), } \mu \mathrm{m}\end{array}$ \\
\hline 14 & AV_TB_LB & $\begin{array}{l}\text { Absolute vibration of the turbine bearing } \\
\text { (left bank, radially), } \mu \mathrm{m}\end{array}$ \\
\hline
\end{tabular}

Original dataset was analysed to identify preliminary correlation. The results of correlation analysis demonstrated a strong linear relationship between the paired parameters (i.e. parameters measured by sensors on the same functional element on different sides). Since it is impractical to consider both parameters in the pair, the analysis is performed for parameters registered by sensors on the left bank. Within the analysed attributes, active power is a regulated parameter that is determined by the power generation plan. 
Table 2. Correlation coefficients between attributes.

\begin{tabular}{|c|c|c|c|c|c|c|c|c|c|c|c|c|c|}
\hline No & 2 & 3 & 4 & 5 & 6 & 7 & 8 & 9 & 10 & 11 & 12 & 13 & 14 \\
\hline 1 & -0.72 & -0.72 & -0.79 & 0.80 & 0.76 & 0.80 & 0.79 & -0.92 & -0.88 & -0.01 & -0.03 & -0.50 & 0.15 \\
\hline 2 & & 0.71 & 0.78 & -0.55 & -0.46 & -0.56 & -0.57 & 0.71 & 0.65 & 0.10 & 0.14 & 0.51 & 0.26 \\
\hline 3 & & & 0.97 & -0.27 & -0.22 & -0.35 & -0.34 & 0.86 & 0.86 & 0.26 & 0.32 & 0.33 & 0.06 \\
\hline 4 & & & & -0.40 & 0.33 & -0.47 & -0.47 & 0.89 & 0.87 & 0.21 & 0.26 & 0.46 & 0.11 \\
\hline 5 & & & & & 0.99 & 0.95 & 0.95 & -0.54 & -0.48 & 0.09 & 0.11 & -0.48 & 0.11 \\
\hline 6 & & & & & & 0.93 & 0.93 & -0.49 & -0.44 & 0,05 & 0.08 & -0.42 & 0.19 \\
\hline 7 & & & & & & & 0.99 & -0.55 & -0.48 & -0.08 & -0.04 & -0.59 & -0.10 \\
\hline 8 & & & & & & & & -0.54 & -0.47 & -0.07 & -0.03 & -0.62 & -0.12 \\
\hline 9 & & & & & & & & & 0.99 & 0.15 & 0.20 & 0.23 & 0.35 \\
\hline 10 & & & & & & & & & & 0.17 & 0.23 & 0.18 & 0.31 \\
\hline 11 & & & & & & & & & & & 0.99 & 0.39 & -0.18 \\
\hline 12 & & & & & & & & & & & & 0.32 & -0.23 \\
\hline 13 & & & & & & & & & & & & & 0.47 \\
\hline
\end{tabular}

The results of correlation analysis allow us to detect the following dependencies. Active power significantly affects the relative vibration of the heel of the thrust bearing (A_POWER RV_HB_LB) and relative vibration of the turbine bearing (A_POWER $\sim$ RV_TB_LB). At the same time, the values of relative vibration of the heel of the thrust bearing and the turbine bearing are strongly related to each other (RV_HB_LB $\sim \mathrm{RV}$ _TB_LB). An inverse relationship is observed between active power and both relative and absolute vibration of the generator bearing (A_POWER -RV_GB_LB, A_POWER -AV_GB_LB). The values of relative and absolute vibration of the generator bearing are also strongly interconnected (RV_GB_LB AV_GB_LB). Moreover, a strong inverse relationship is observed between active and reactive power (A_POWER -R_POWER). Correlation analysis of the initial data has allowed us to establish the presence of relations between key parameters, determine the strength of their influence on each other and figure out the general characteristic patterns of the system.

\section{Multi-dimensional Analysis of Vibration Monitoring Data}

\subsection{Principal Component Analysis}

In order to apply the multi-dimensional data analysis, we formed a dataset which contains 1229 objects and 8 attributes. The principal component analysis was implemented to reduce the dimension of multi-dimensional space and identify patterns in the structure of multi-dimensional data. In general, the method allows identifying $k$ components based on $k$ initial attributes. Table 3 shows the results of calculating the eigenvectors of the covariance matrix arranged in order of descending eigenvalues. 
Table 3. Results of principal component calculation.

\begin{tabular}{|c|c|c|c|c|c|c|c|c|}
\hline Components & 1 & 2 & 3 & 4 & 5 & 6 & 7 & 8 \\
\hline Eigenvalues & 0.543 & 0.192 & 0.137 & 0.091 & 0.027 & 0.008 & 0.002 & 0.001 \\
\hline $\begin{array}{l}\text { Accumulated } \\
\text { dispersion }\end{array}$ & 0.543 & 0.734 & 0.871 & 0.962 & 0.989 & 0.997 & 0.999 & 1.000 \\
\hline 1 A_POWER & 0.466 & 0.128 & 0.072 & 0.007 & 0.219 & 0.294 & 0.755 & 0.238 \\
\hline R_POWER & -0.394 & 0.225 & 0.061 & -0.388 & 0.788 & -0.058 & -0.041 & 0.121 \\
\hline RV_GB_LB & -0.406 & 0.254 & -0.287 & -0.237 & -0.296 & 0.727 & 0.073 & -0.103 \\
\hline RV_HB_LB & 0.362 & 0.359 & -0.373 & -0.307 & -0.160 & -0.118 & -0.341 & 0.592 \\
\hline RV_TB_LB & 0.393 & 0.148 & -0.482 & -0.194 & 0.197 & -0.105 & -0.014 & -0.710 \\
\hline AV_GB_LB & -0.413 & 0.038 & -0.453 & 0.015 & -0.202 & -0.540 & 0.530 & 0.096 \\
\hline AV_FH_LB & -0.413 & 0.585 & -0.123 & 0.768 & 0.180 & 0.041 & -0.117 & 0.001 \\
\hline AV_TB_LB & -0.074 & 0.612 & 0.563 & -0.269 & -0.325 & -0.253 & 0.109 & -0.234 \\
\hline
\end{tabular}

The combination of Kaiser's rule and the Broken-stick model [12] helped to identify four principal components (PC1, PC2, PC3 and PC4). Figure 1 illustrates the eigenvalues of components. As Figure 1 shows, Kaiser's rule determines one principal component - eigenvalue of the first component is significantly greater than the average value; the Broken-stick model gives four principal components - the line of Broken-stick model cuts off the eigenvalues of first four components.

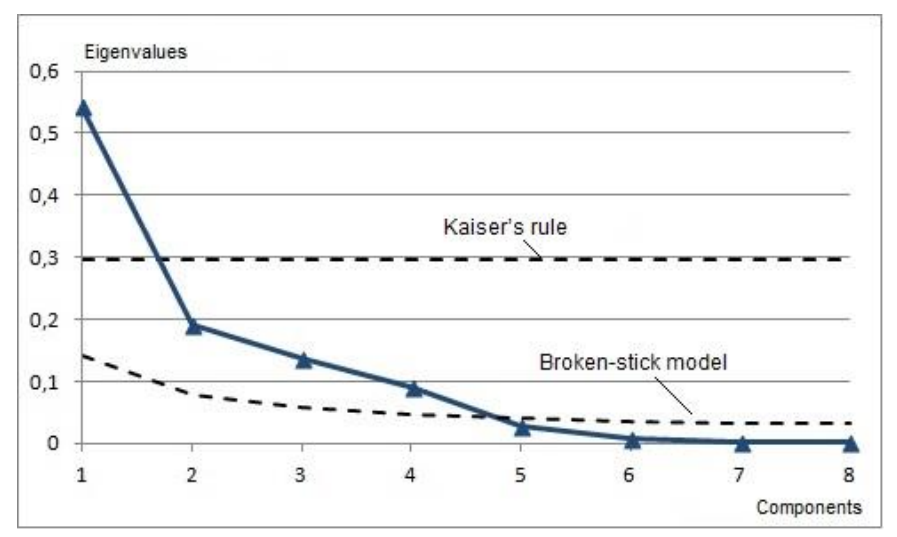

Fig. 1. Eigenvalues of components.

The nature of the principal components is described by the weights of the attributes (i.e. eigenvalues) presented in Table 3 . We can see that the first principal component (PC1) is characterised by a significant positive contribution of active power, relative vibration of the heel of the thrust bearing and the turbine bearing and a significant negative contribution of absolute and relative vibration of the generator bearing and reactive power. Obviously, the first component demonstrates all strong relations iden- 
tified at the stage of correlation analysis. The second principal component (PC2) is characterised by a significant positive contribution of absolute vibration of the heel of the thrust bearing and the turbine bearing as well as a positive contribution of relative vibration of the heel of the thrust bearing. The third principal component (PC3) is characterised by a significant positive contribution of absolute vibration of the turbine bearing, a significant negative contribution of relative vibration of the turbine bearing, absolute vibration of the generator bearing and negative contribution of relative vibration of the heel of the thrust bearing. The fourth principal component is characterised by a significant positive contribution of absolute vibration of the heel of the thrust bearing and negative contribution of reactive power. Taking into account the high information content of the first and second main components in the data structure ( $73 \%$ of accumulated dispersion), the further multi-dimensional analysis and interpretation of its results are performed in the context of the first two principal components.

\subsection{Cluster Analysis}

In order to identify the structure and discover patterns within the data, the cluster analysis was performed using the common centroid-based clustering method $k$-means. The $k$-means clustering is done by minimizing the sum of squares of distances between data and the corresponding cluster centroid. For $k$-means method, the most important and difficult question is the identification of the number of clusters that should be considered. In this study, the number of clusters was determined through the PCA technique: the number of clusters that depend on the number of principal components. Thus, referring back to the previous section, four principal components form the five-cluster structure $(\mathrm{k}=5)$. The results of the clustering of the studied multidimensional dataset on the PCA plot are presented in Figure 2.

The analysed objects are divided into three large groups that are characterised by low, medium and high values of active power. In the largest group, where high values of active power are observed, additional three clusters stand out by the values of vibrations. Thus, the five-cluster data structure includes: Cluster 1 (blue) -24 objects, Cluster 2 (green) - 349 objects, Cluster 3 (light blue) - 114 objects, Cluster 4 (yellow) -415 objects and Cluster 5 (red) -327 objects.

The data distribution as per the clusters in terms of parameters is presented in Figure 2 as a set of histograms. Cluster 1 (blue) (2\% of data) differs from other clusters, it is characterised by low values of active power (appr. $120 \mathrm{MW}$, Fig. 2a) and all other parameters that correspond to the moments when the hydraulic unit is stopped or started. Cluster 2 (green) (28\% of data) is characterised by average values of power activity (appr. $215 \mathrm{MW}$, Fig. 2a) and rather high values of other parameters including maximum values of absolute and relative vibration of the generator bearing (Fig. 2c and $2 \mathrm{~d}$ ). Cluster 3 (light blue) (9\% of data) is characterised by maximum values of active power (appr. $430 \mathrm{MW}$, Fig. 2a) and maximum values of absolute vibration of the heel of the thrust bearing support and the turbine bearing (Fig. 2e and 2h). Cluster 4 (yellow) (34\% of data) is characterised by close to maximum values of active power (appr. 415 MW, Fig. 2a), maximum values of relative vibration of the turbine bearing (Fig. 2g) and close to minimum values of absolute and relative vibration of the gener- 
ator bearing (Fig. 2c and 2d). Cluster 5 (red) (27\% of data) is characterized by high values of active power (appr. $400 \mathrm{MW}$, Fig. 2a), minimum values of reactive power (Fig. 2b), minimum values of absolute and relative vibration of the generator bearing (Fig. 2c and 2d) and low values of the absolute vibration of the heel of the thrust bearing (Fig. 2e) and the turbine bearing (Fig. 2h). Highlighted clusters combine the moments of time with typical behaviour of the system that corresponds to different modes and conditions in which the power generating equipment operates.
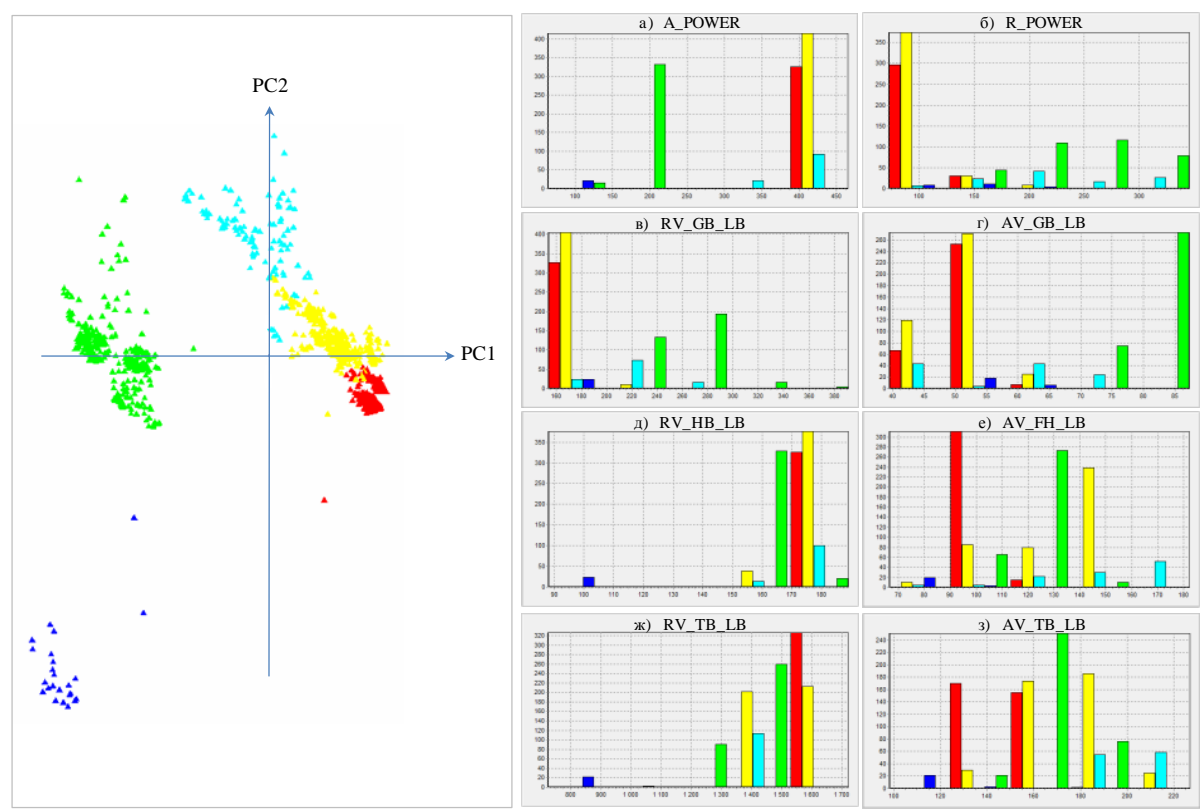

Fig. 2. Five-cluster data structure.

In order to study the dependencies between the parameters in certain modes and conditions of operation of the hydraulic unit, the obtained clusters were analysed in a more detailed way in this research. As an example, consider Cluster 2 (green) of the five-cluster structure. The moments of time combined by this cluster correspond to the average level of active power, but, at the same time, the values of vibration of the generator bearing reach their maximum. To analyse the nature of the system behaviour at high values of particular parameters the data were clustered over a range of values of these parameters. Figure 3 shows the results of clustering over the range of values of relative vibration of the generator bearing in the plane of the first two principal components. The colour of points in the figure corresponds to a certain range of values: blue colour indicates the lowest values of the parameter, red colour indicates the highest values of the parameter. On the data map, there is an area that includes five objects from Cluster 2 with maximum values of relative vibration of the generator bearing. 


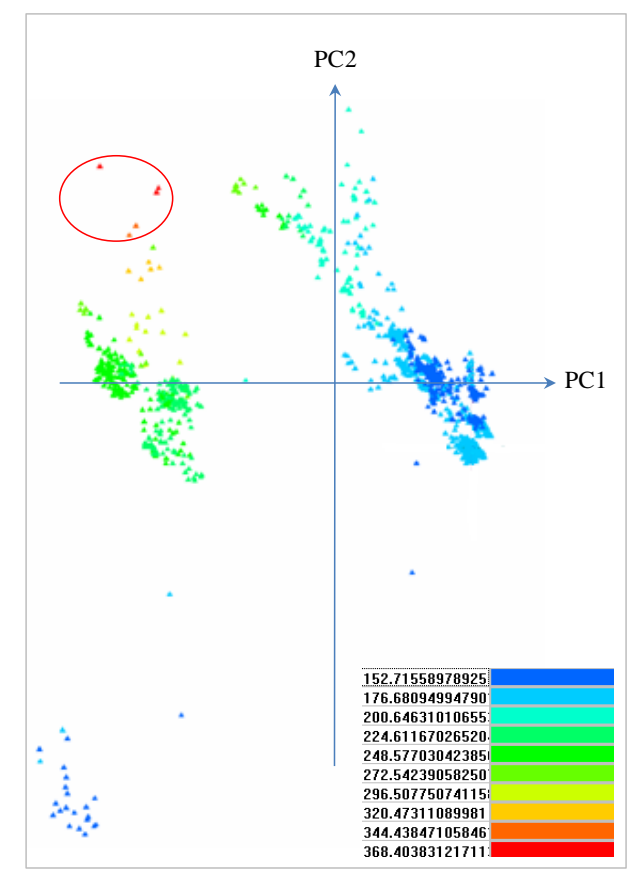

Fig. 3. Results of clustering over the range of values of relative vibration of the generator bearing (RV_GB_LB) on the PCA plot.

To analyse the dependencies between the monitoring parameters, the considered moments of time were detailed to minutes and a comparative diagram for the time series of monitored parameters for one of the characteristic periods of time was constructed (Fig. 4). Figure 4 covers the period of time from 19:00 h to 22:00 h on $21^{\text {st }}$ August 2015. The area marked with vertical lines depicts one of the characteristic periods of time from 20:00 $\mathrm{h}$ to 21:00 $\mathrm{h}$ when the values of relative vibration of the generator bearing (RV_GB_LB) are at their maximum. As Figure 4 shows, a change in active power at the upper limit of average values and an increase in reactive power lead to an increase in relative vibration of the generator bearing (RV_GB_LB) (appr. 60\%) and a significant increase in absolute vibration of the heel of the thrust bearing (AV_FH_LB) (appr. 45\%) and absolute vibration of the turbine bearing (AV_TB_LB) (appr. 17\%), however the values of absolute vibration of the generator bearing (AV_GB_LB) remain unchanged. Apart from this, in the considered period, there is an increase in the relative vibration of the heel of the thrust bearing (RV_HB_LB) and the turbine bearing (RV_TB_LB). This behaviour was observed mainly in the evening from 19:00 h to 22:00 h with the duration of not more than one hour per day in the second half of August. 


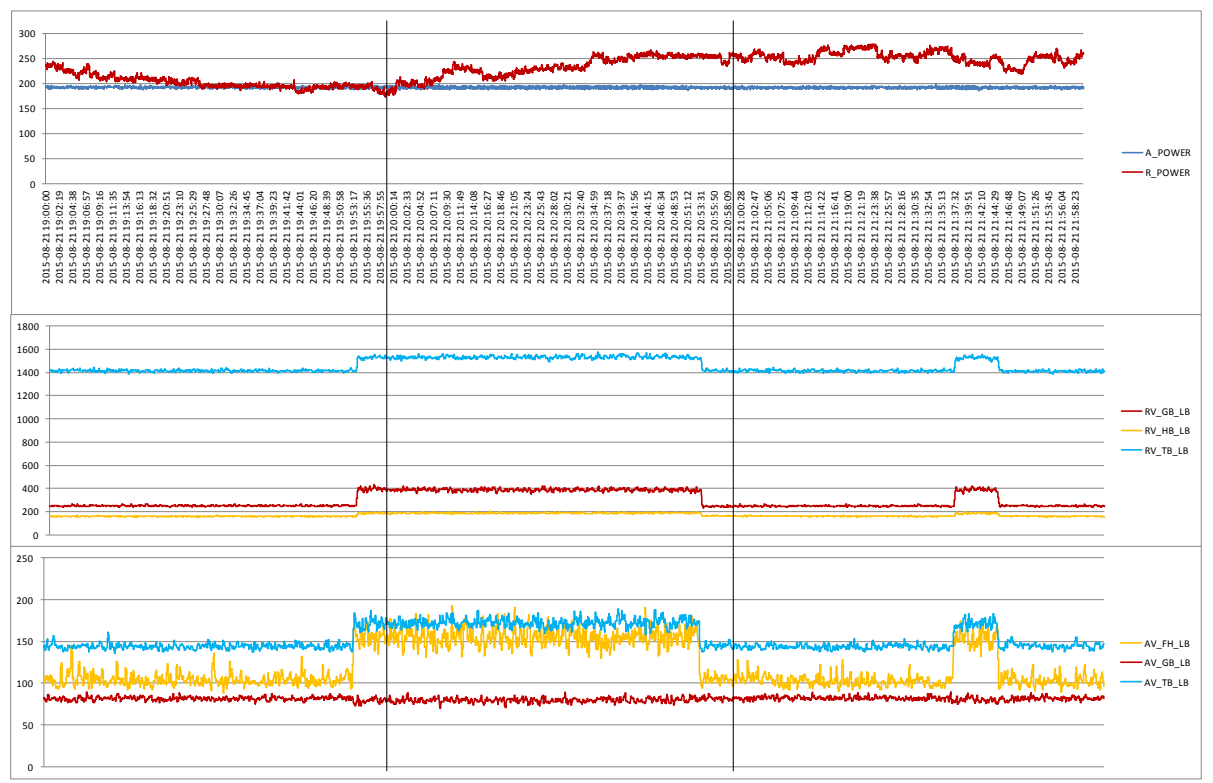

Fig. 4. Diagram of comparing the time series of monitored parameters at the moments with high values of RV_GB_LB.

Figure 5 shows the candlestick charts where the upper and lower shadows set the minimum and maximum value of the parameter in the original dataset. This graph demonstrates the relationship between the values of the main parameters and their ranges in the analyzed time interval.

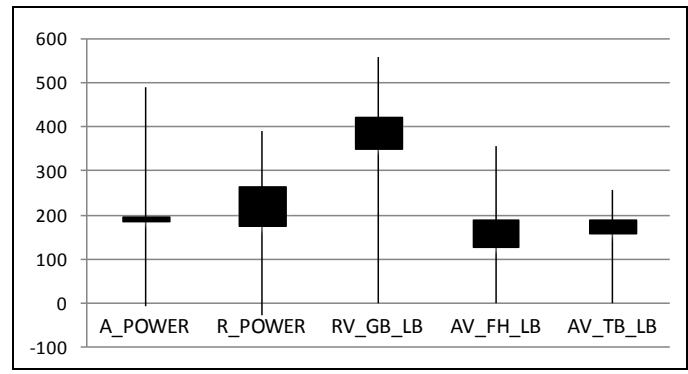

Fig. 5. Diagram of parameter ratios in the moments of time with maximum values of RV_GB_LB.

As another example, consider Cluster 5 (red) of the five-cluster structure. The moments of time combined by this cluster correspond to the high level of active power, but, at the same time, the values of vibration of the generator bearing reach their min- 
imum, whereas the values of relative vibration of the heel of the thrust bearing and the turbine bearing are quite high. Figure 6 shows the results of clustering over the range of values of relative vibration of the turbine bearing in the plane of the first two principal components. On the data map, there is an area that includes the 215 objects from Cluster 5 with high values of relative vibration of the turbine bearing.

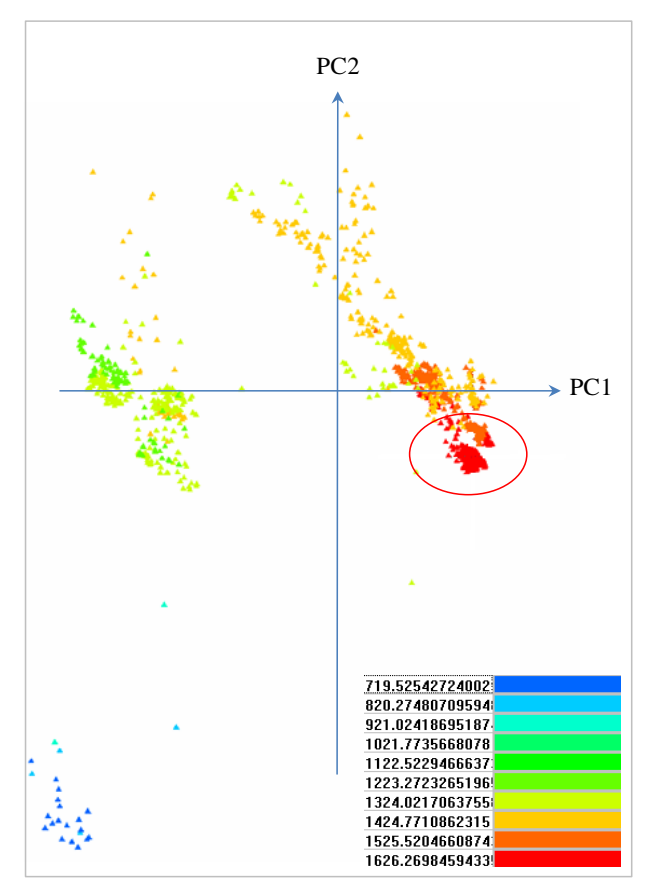

Fig. 6. Results of clustering over the range of values of relative vibration of the turbine bearing (RV_TB_LB) on the PCA plot.

In a similar vein, the considered moments of time were detailed to minutes and another comparative diagram for the time series of monitored parameters for one of the characteristic periods of time was constructed (Fig. 7). Figure 7 covers the period of

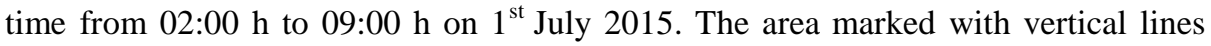
depicts one of the characteristic periods of time from 05:00 $\mathrm{h}$ to 06:00 $\mathrm{h}$ when the values of relative vibration of the turbine bearing (RV_TB_LB) are high. As Figure 7 suggests, a slight decrease in active power in the range of high values (appr. 450MW) leads to a slight decrease in relative vibration of the turbine bearing (RV_TB_LB) and to a significant increase in absolute vibration of the heel of the thrust bearing (AV_FH_LB) (appr. 50\%) and in absolute vibration of the generator bearing (AV_GB_LB) (appr. 30\%). This behavior of the system was mainly observed in the daytime continuously up to 16 hours at the end of June or at the beginning of July. 


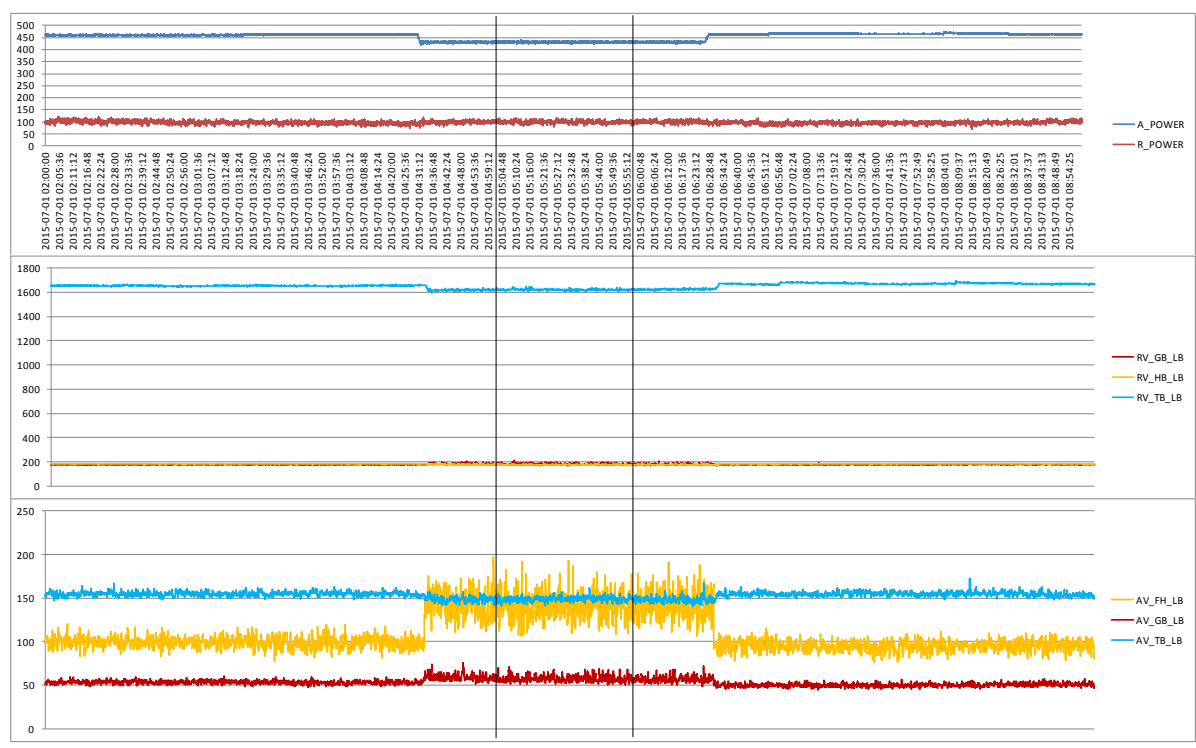

Fig. 7. Diagram of comparing the time series of monitored parameters at the moments with high values of RV_TB_LB.

Figure 8 shows a candlestick chart that illustrates comprehensively the relationship between values and ranges of key parameters in the analyzed time interval. It should be noted that the observed high values of relative vibration of the turbine bearing $($ appr.1600 $\mu \mathrm{m})$ are a distinctive feature and property of the researched hydraulic unit.

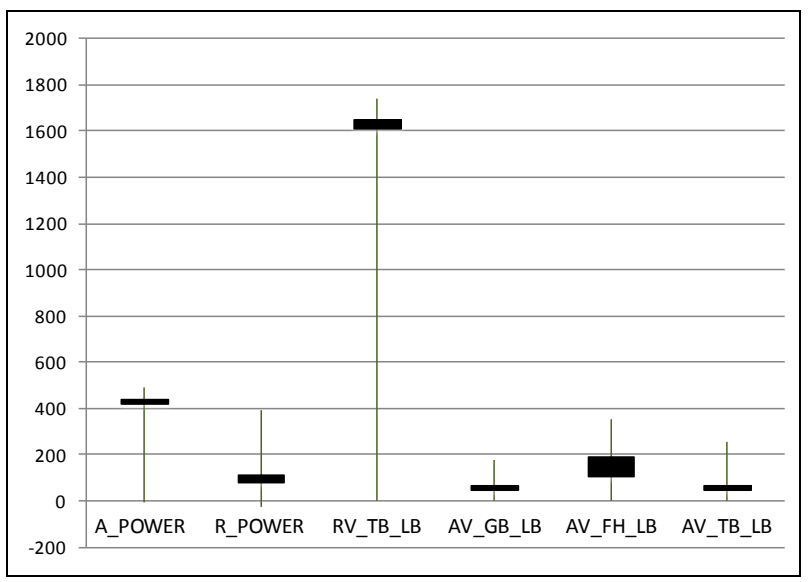

Fig. 8. Diagram of parameter ratios in the moments of time with high values of RV_TB_LB. 
The comprehensive multi-directional analysis of monitoring data has allowed us to determine the periods when the hydraulic unit manifests its typical behaviour and the operating conditions characteristic for them, identify dependencies between parameters and their influence on each other and on the behavior of the system as a whole considering the accepted values. The modes of operation that lead to high values of vibration can be considered as adversely increasing the equipment wear, which must be taken into account when assessing the technical condition and managing the hydraulic unit life.

\section{Conclusion}

This paper presents the study of features of the hydraulic unit operation carried out on the basis of comprehensive analysis of monitoring data of the vibration control system. Application of the multi-dimensional data analysis techniques - principal component analysis and cluster analysis - identified the moments of time with the typical behaviour of the system that correspond to various modes and conditions in which the hydropower equipment operates.

It was determined that at an average level of active power the vibration of the generator bearing reaches its maximum values, whereas at a high level of active power it is minimal, but the relative vibration of the heel of the thrust bearing and the turbine bearing has quite high values. Moreover, the low level of reactive power corresponds to a high level of active power. Also, this study has allowed us to detect the evidence of mutual influence of functional elements of the hydraulic unit in various modes of its operation. The turbine bearing and the thrust bearing proved to have a similar behaviour pattern, their relative vibration increases with a raise in the active power level whereas absolute vibration, on the contrary, decreases. At the same time, the behaviour of the generator bearing is different, its absolute and relative vibration decreases with a raise in the active power level.

The detailed analysis of the characteristic moments of time has allowed us to identify the dependencies of the accepted values for key parameters. For instance, a slight change in the amplitude of active power at the upper limit of average values (appr. $200 \mathrm{MW}$ ) leads to a significant increase in the relative vibration of the generator bearing (appr. 60\%), absolute vibration of the heel of the thrust bearing (appr. 45\%) and absolute vibration of the turbine bearing (appr. 60\%); a slight decrease in active power in the range of high values (appr. 450MW) leads to a slight decrease in the relative vibration of the turbine bearing (in the range of its maximum values, appr. $1600 \mu \mathrm{m}$ ) and to a significant increase in the absolute vibration of the thrust bearing support (appr. 50\%) and in the absolute vibration of the generator bearing (appr. 30\%).

The revealed dependencies between parameters, ranges and ratios of their values in various operating modes present the unique characteristics and distinctive properties of the particular hydraulic unit and jointly form the so-called "analytical portrait" of the hydraulic unit. A change in the technical condition of the hydraulic unit over time may manifest itself in a change in the detected dependencies between parameters, and therefore by comparing the "analytical portraits" it will be possible to identify the dynamics of equipment wear. Formalisation and verification of statistical reliability of the identified dependencies and characteristic ratios of the parameter values will help 
form a knowledge base with the acceptable and unacceptable modes of the hydraulic unit operation and the features of its behaviour in various conditions. The technological basis that is being developed will provide a new solution for analytical assessment of the state of equipment without putting it out of operation and resource management of the energy system.

\section{References}

1. Gurinovich V.D., Savelev V.A., Yanchenko Yu.A.: Metodologicheskie aspekty perekhoda na tekhnicheskoe obsluzhivanie $\mathrm{i}$ remont $\mathrm{s}$ uchetom tekhnicheskogo sostoyaniya oborudovaniya [Methodological aspects of the transition to maintenance and repair taking into account the technical condition of the equipment]. Metodicheskie voprosy issledovaniya nadezhnosti bolshikh sistem energetiki: sbornik statey. [Methodical issues of the study of the reliability of large energy systems: a collection of articles], Iss. 66., pp. 448-454 (2015) (in Rusian).

2. Gurinovich V.D., Yanchenko Yu.A., Savelev V.A.: Zadachi, problemy i usloviya perekhoda na tekhnicheskoe obsluzhivanie i remont energeticheskogo oborudovaniya po tekhnicheskomu sostoyaniyu. [Tasks, problems and conditions of transition to the maintenance and repair of power equipment based on the technical condition]. Metodicheskie voprosy issledovaniya nadezhnosti bolshikh sistem energetiki: sbornik statey. [Methodical issues of the study of the reliability of large energy systems: a collection of articles], Iss. 68., pp. 634-642 (2017) (in Rusian).

3. Kovalev A.V., Trushin N.N., Salnikov V.S.: Prognozirovanie tekhnicheskogo sostoyaniya tekhnologicheskogo oborudovaniya. [Forecasting the technical condition of technological equipment]. Izvestiya TulGU. Tekhnicheskie nauki. [News of Tula State University. Technical science]. 2014. Iss. 11. Part. 2. P. 554-559 (in Rusian).

4. Akhmetkhanov R.S., Dubinin Ye.F., Kuksova V.I.: Metod klasterizatsii diagnosticheskikh dannykh pri vibrodiagnostike tekhnicheskikh system. [The clustering method of diagnostic data for vibration diagnostics of technical systems]. Vestnik nauchno-tekhnicheskogo razvitiya. [Bulletin of scientific and technological development], No. 5(117), pp. 3-16 (2017) (in Russian).

5. Standart organizatsii: Gidroelektrostantsii. Metodiki otsenki tekhnicheskogo sostoyaniya osnovnogo oborudovaniya [Organization standard: Hydroelectric power stations. Methods for assessing the technical condition of the main equipment], STO 70238424.27.140.0012011. Order of NP "INVEL" of 01.04.2011 No. 25 (in Rusian).

6. Metodika otsenki tekhnicheskogo sostoyaniya osnovnogo tekhnologicheskogo oborudovaniya i liniy elektroperedachi elektricheskikh stantsiy i elektricheskikh setey [Methods of assessing the technical condition of the main technological equipment and power lines of power plants and electrical networks]. Prikaz Ministerstva energetiki Rossiyskoy Federatsii ot 26.07.2017 № 676. [Order of the Ministry of Energy of the Russian Federation of 26.07.2017 No. 676] (in Rusian).

7. Penkova T., Korobko A., Valov Yu. Issledovaniye osobennostey funktsionirovaniya gidroagregata na osnove kompleksnogo analiza dannykh vibratsionnogo kontrolya [The study of features of hydraulic unit functioning based on the comprehensive analysis of vibration control system data]. Pribory i sistemy. Upravleniye, kontrol', diagnostika. [Instruments and systems. Management, monitoring, diagnostics], No. 12, pp.36-45 (2018), doi 10.25791/pribor.12.2018.000 (in Rusian). 
8. Abdi H., Williams L.: Principal Components Analysis. Wiley Interdisciplinary Reviews. Computational Statistics 2(4), 439-459 (2010).

9. Jain A., Dubes R.: Algorithms for Clustering Data. Michigan State University. Prentice Hall (1988).

10. Williams G.J., Simoff S.J.: Data Mining: Theory, Methodology, Techniques, and Applications. Springer. (2006).

11. Gorban A., Pitenko A., Zinovyev A.: ViDaExpert: user-friendly tool for nonlinear visualization and analysis of multidimensional vectorial data. Cornell University Library (2014) URL http://arxiv.org/abs/1406.5550.

12. Peres-Neto P., Jackson D., Somers K.: How many principal components? Stopping rules for determining the number of non-trivial axes revisited. Computational Statistics \& Data Analysis 49(4), 974-997 (2005). 